\title{
Unhealthy, Unwealthy and Left Behind - Workforce Participation and Inequality Among Older Australians
}

\author{
Huong Dinh \\ Australian Treasury
}

Lyndall Strazdins

Australian National University Research School of Population Health

Tinh Doan ( $\nabla$ tinh.doan@anu.edu.au )

Australian National University https://orcid.org/0000-0002-2297-8187

Thuy Do

Australian National University

Amelia Yazidjoglou

Australian National University Research School of Population Health

Cathy Banwell

Australian National University Research School of Population Health

\section{Research}

Keywords: older people, employment, health, economic inequality, Australia

Posted Date: February 25th, 2021

DOI: https://doi.org/10.21203/rs.3.rs-241289/v1

License: (c) (i) This work is licensed under a Creative Commons Attribution 4.0 International License. Read Full License 


\section{Abstract}

\section{Background}

Australians born in 2012 can expect to live about 33 years longer than those born 100 years earlier. However, only seven of these additional years are spent in the workforce. Longer life expectancy has driven policies to extend working life and increase retirement age, the current Australian policy, which has increased the eligibility for the pension from 65 to 67 by 2023 , assumes that an improvement in longevity corresponds with an improvement in health expectancy. However, there is mixed evidence of health trends in Australia over the past two decades. Although some health outcomes are improving among older age groups, many are either stable or deteriorating. This raises the question of how health trends intersect with policy for older Australians aged from 50-70. This paper considers the interplay between older workers' health and workforce participation rates over the past 15 years when extended workforce participation has been actively encouraged.

\section{Methods}

We compared health and economic outcomes of the older people in following years with the base year (start of the study period), adjusting for some key socio-economic characteristics such as age, sex, ethnicity, education and equivalized household income by applying the Random effects estimator with maximum likelihood estimation technique.

\section{Results}

We find that regardless of increasing longevity, the health of older adults aged between 50-70 has slightly deteriorated. In addition, health gaps between those who were working into their older age and those who were not have widened over the 15year period. Finally, we find that widening health gaps linked to workforce participation are also accompanied by rising economic inequality in incomes, financial assets and superannuation. With the exception of a small group of healthy and very wealthy retirees, the majority of the older Australians who were not working had low incomes, assets, superannuation, and poor health.

\section{Conclusions}

The widening economic and health gap within older population over time indicates a clear and urgent need to add policy actions on income and health, to those that seek to increase workforce participation among older adults.

\section{Introduction}

In Australia, like many affluent nations, life expectancy at birth for people born in 2012 compared to those born at Federation (1901) has increased approximately 33 years, however, based on recent trends only seven of these additional years are spent in the workforce [1]. The discrepancy between life expectancy and labour force participation, in combination with an aging population, has ramifications for government spending and the financial security of older Australians. Therefore, policies and practices to encourage and extend workforce participation are at the forefront of the many Government's agendas.

The current Australian policy, which has increased the eligibility for the pension from 65 to 67 by 2023, assumes that an improvement in longevity corresponds with an improvement in health expectancy. However, there is mixed evidence of health trends in Australia over the past two decades. Although some health outcomes are improving among older age groups, many are either stable or deteriorating. There has been a 2-3 per cent improvement in arthritis for older age groups (45-54, 55-64 and 65-74) in 2014-15 when compared with the same age-group in 2004-05. Cancer seems to remain stable but rates of diabetes, heart, stroke and vascular disease are increasing [2, 3].

This mixed evidence raises the question of how health trends intersect with policy for older Australians aged from 50-70. This paper considers the interplay between older workers' health and workforce participation rates over the past 15 years when extended workforce participation has been actively encouraged. 
The aim of the present study was to examine the health profile of this population over time using the HILDA data. We then sought to answer the question of what drives the widening health gap between those remaining in the workforce as they age, and those who do not. We aimed to provide new insights into the interrelationships between health, employment and economic resources among older workers who are the target of government efforts to extend their working life and reduce their costs on the economy. We have gained further insight into widening economic and health inequality amongst older people, including that living longer is not necessarily living with better health. Our findings contradict the assumption, which was used to support the current Australian retirement age extension, that people today live longer, healthier lives and are therefore able to extend their working lives.

\section{Previous Research}

Internationally, the health of older adults, termed health expectancy, has not generally improved at the same rate as overall longevity [25]. For example, in the Netherlands a healthy life, defined as without major illness or disability or a morbidity-free life expectancy as a percentage of total life expectancy, decreased significantly from $69.2 \%$ in 1989 to $63.3 \%$ in 2000 for women and from $74.2 \%$ to $71.4 \%$ for men [24]. Similarly, in Australia, the proportion of adults living a healthy life remained constant between 2003 and 2011 at around 88\% despite longevity increasing [19]. This discrepancy between longevity and health has significant consequences for older workers.

The health of older workers impacts on their ability to continue working. Approximately $42 \%$ of British workers aged 50-64 live with a health condition or disability and six out of ten Australian workers reported involuntary retirement due to poor health [23, 27]. Due to the significant impact of health on employment, there are major health disparities between those who work or can work and those who cannot. For example, $27 \%$ of people without chronic disease are more likely to work beyond the recommended retirement age compared to $23 \%$ people with a chronic disease [21]. A diagnosis of diabetes is associated with a $30 \%$ increase in the rate of labour-force exit in Europe and the US [26]. Furthermore, older working-class employees face a higher rate of poor health and disability, due to occupational hazards and physically demanding jobs [28]. For adults over 50 years old, after a short period of unemployment, those with good health are more likely to return to work than those with poor health. Further, job loss or unemployment is associated with an increased risk in morality and cardiac events [22]. Among older workers those remaining in employment for longer are healthier than their unemployed or involuntarily retired counterparts [4, 21]. Along with diverging health outcomes, a similar widening is occurring in economic resources in the older population [20, 26].

Gains in life and health expectancy are disproportionately occurring among more affluent individuals [20]. Health and income form part of a virtuous cycle over the life-course which, in older age, mean that, good health enables a life time benefit of longer work force participation and accumulated income and wealth, whilst the health expectancy of lower-income workers remained stable or in some cases has declined [20]. In Australia, those in the highest socioeconomic group expect seven more years of full health for men and 4.8 more years for women than those in the lowest socioeconomic group [19]. Thus there is an increasing number of older, healthier and highly educated workers remaining employed for longer whilst those with poorer health, less education and less earning capacity have less ability to prolong their workforce participation [28]. Despite policy to encourage the participation of older adults in the work force, health becomes an increasingly important barrier for extending working lives and therefore an influential factor for the expansion of socio-economic inequalities in the older population.

Policy targets that treat all older population the same are likely to be ineffective, due to rising health and economic inequality amongst older people $[20,28]$. For example, there are some people who are wealthy and healthy, who may not want to work or choose to retire early, while there are others who need income and employment but their poor health restricts them from labour market participation. A monolithic policy for the older population is likely to have negative unintended consequences on some groups. This study decomposes the population of 50-70 year olds into subgroups based on their economic resources and health to help uncover detailed interrelationships between health and employment among this population. Understanding how the older population fares in terms of their health is crucial for informing policy relating to healthy and productive aging.

We hypothesise that:

Page $3 / 25$ 
$\mathrm{H} 1$ : Although there has been an increase in labour-force participation of older workers the health profile of employed older workers has not improved. That is, improved workforce participation rate does not necessarily reflect only health improvements, but also other reasons e.g. financial needs.

H2: Health gaps between the employed and non-employed older population have also widened.

H3: The widening health gap is accompanied by widening income, superannuation, and net financial asset gaps.

\section{Materials And Methods}

\subsection{Data and sample}

Data. To test the hypotheses above, we used waves 1-15 of the Household Income and Labour Dynamics in Australia (HILDA) data which is highly valued for informing policy relating to healthy and productive ageing [8]. This survey, which commenced in 2001, is a nationally representative household-based panel study of Australian adults aged 15 years and over. Each wave consists of about seven thousand households or over, and covers at least 17,000 household members. The survey asked respondents about their employment, economic resources, family circumstances, health and socio-economic characteristics through face-to-face interviews and self-complete questionnaires. Response rates were consistently high, and the retention rate was $86 \%$ in wave 2 , and above $90 \%$ in following waves [9].

Sample. Our current study focuses on older people aged 50 to 70 in each wave who reported on physical functioning, mental health, general health, health conditions, and other individual characteristics and socio-economic factors. We focus on this age group as they are transitioning into retirement when health and employment interplay most during life course. Because people are ageing over time, this sample automatically includes new people who entered the age bracket (50-70) and excludes those who exited the age upper bound in later years. The final sample includes 60,723 observations of which 3,039 unique $(\mathrm{N}=28,787)$ are males and 3,138 unique $(\mathrm{N}=31,936)$ are females over 15 years. Because of the age cut-offs, attrition and recruitment of new respondents, the number of observations varies across waves.

\subsection{Measures of health outcomes}

In this paper, we focused on four key health outcomes based on self-reported responses on mental health, physical functioning, general health, and number of health conditions.

Mental health was constructed from five items of the Short Form 36 (SF-36) health status questions [10]. The mental health scale is widely used in population-based surveys, performing best among the eight SF-36 health scales in cross-sectional and longitudinal analyses of patients with clinical distress [11]. Physical functioning was constructed from 10 items of the SF-36, which assess physical capacities in various activities. General health was constructed from five items which assessed selfassessed general health. These health measures were re-coded on a 0-to-100 scale with a higher score meaning better health [see, 9].

Table 1: Health measures and definition 


\begin{tabular}{|c|c|}
\hline Health measures & HILDA subcomponents and scale \\
\hline \multirow{5}{*}{$\begin{array}{l}\text { Mental Health } \\
\text { (score 0-100) }\end{array}$} & Been a nervous person? $(1-6 ; 1$ : all of the time -6 none of the time) \\
\hline & Felt so down in the dumps nothing could cheer you up (1-6)? \\
\hline & Felt downhearted and blue (1-6)? \\
\hline & Felt calm and peaceful (1-6)? \\
\hline & Been a happy person (1-6)? \\
\hline \multirow{10}{*}{$\begin{array}{l}\text { Physical functioning } \\
\text { (score 0-100) }\end{array}$} & Vigorous activities (1-3: 1 limited a lot, 2 limited a little, 3 not limited at all) \\
\hline & Moderate activities (1-3) \\
\hline & Lifting or carrying groceries (1-3) \\
\hline & Climbing several flights of stairs (1-3) \\
\hline & Climbing one flight of stairs (1-3) \\
\hline & Bending kneeling or stooping (1-3) \\
\hline & Walking more than one kilometer (1-3) \\
\hline & Walking half a kilometer (1-3) \\
\hline & Walking 100 metres (1-3) \\
\hline & Bathing or dressing yourself (1-3) \\
\hline \multirow{5}{*}{$\begin{array}{l}\text { General } \\
\text { Health } \\
\text { (score 0-100) }\end{array}$} & Self-assessed health (from 1-excellent to 5-poor) \\
\hline & Get sick a little easier than other people (1-definitely true to 5-definitely false) \\
\hline & As healthy as anybody I know (1-5) \\
\hline & Expect my health to get worse (1-5) \\
\hline & My health is excellent (1-5) \\
\hline
\end{tabular}

Apart from the three main health measures above, we also examined the 'number of health conditions' which was collected from wave three (2003) onwards, respondents were asked if they had any specific long-term health conditions in the list of 17 health states (yes/no questions). For the details of these variable and its components, see [9]. A total health condition index was created by taking the sum of all (17) incurred health conditions.

\subsection{Economic outcome variables}

In this paper, we also considered some key economic outcomes that may be associated with the older population's employment and health. They are: (1) regular private income, the sum of a financial year regular market income (wages and salary, business income, investment income, and regular private pension income), and regular private transfers; (2) income from all sources, the sum of regular private income and Australian and foreign pensions, and social welfare benefits (but irregular income such as one-off payment, lottery prize... is excluded); (3) superannuation, the sum of retiree and non-retiree superannuation, and it is accumulated over time. Superannuation data is available in only waves 2, 6, 10 and 14 only; (4) net financial assets exclude property assets and property debts, and business assets and business debts. We excluded property and business assets as they are not directly related to wage labour market outcomes. The net financial assets, those remaining after debts e.g. credit card debts, overdraft account, overdue bills, capture superannuation, saving on bank accounts, bank account balance, cash and equity investments, trust funds and life insurance. 


\subsection{Covariates}

In the prediction models for health outcomes, income, net financial assets, and superannuation, we adjusted for gender, ethnicity, age, education, and equivalized household income to remove the influence of these factors on the outcomes because they were not attributable to working status. All variables in monetary terms were discounted to 2002 price level using the annual Consumer Price Index (CPI). Below are definitions of variables and covariates.

Gender takes value 1 for male and 0 for otherwise. Ethnicity takes four values 1 for non-indigenous Australian, 2 for Aboriginal and Torres Strait Islander status, 3 for other English-speaking migrants, and 4 for non-English speaking migrants. Age is a continuous variable ranging from 50 to 70 as we focused on the older labour force. Education is a dummy variable taking value 1 for tertiary education, and 0 for otherwise. Equivalized income per capita, computed from household financial year disposable regular income, is the household's financial year gross regular income after income taxes. As this variable was measured at household level, we adjusted for the household composition using the modified OECD equivalence scale ${ }^{1}$.

\subsection{Statistical approach}

Individual and socio-economic characteristics were used as predictors for health outcomes in the models, as follows:

$$
y_{i t}=\mathbf{X}_{\dot{t i t}} \boldsymbol{\beta}+\boldsymbol{\varepsilon}_{\dot{i t}} \quad \text { where } \boldsymbol{\varepsilon}_{i t}=\alpha_{i}+\eta_{\text {it }}
$$

$y_{i t}$ is health outcomes for individual $i$ in year $t, X$ is a vector of individual and household characteristics such as age, gender, ethnicity, education, and equivalized income per capita in logarithm. We also controlled for wave or time effect in the model. Instead of using raw health outcomes, we adjusted for these important factors affecting individual's health outcomes, however, our model does not aim to examine a causal relationship between the covariates and health outcomes.

The error terms $\left(\varepsilon_{i t}\right)$ has two parts, a time-invariant component $\left(a_{i}\right)$ that differs across individuals and a component $\left(\eta_{i t}\right)$ that is independent of both time and individuals. The individual component $a_{i}$ may be correlated with the variables in $\mathbf{X}_{i t}$ (fixed effects model, FE) or uncorrelated with $\mathbf{X}_{i t}$ (random effects, RE).

We employed the RE estimator with maximum likelihood estimation technique. Two-level maximum likelihood regression was used: the first level assumes fixed effects for demographic covariates while the second assumes random effects within individuals. This approach allows inclusion of both within- and between-individual effects and addresses limitations present in the fixed-effect models, which only examines within-individual effects [12,13]. Our approach overcomes problems of imprecise estimates with large standard errors if predictors vary between individuals but doesn't vary over time, e.g., sex, ethnicity, or does not vary or vary very little over time e.g. education [14]. The prediction of the economic outcomes such as income, net financial assets and superannuation used the similar model for health outcomes as in equation (1), but we did not control for the equivalized household income as we did in the health models.

The analyses were stratified by working status (being employed versus being unemployed) to predict health outcomes for each group in order to examine how the predicted health outcomes by each group changed over the considered period (2001-2015). The model for each health outcome was conducted for the population aged 50-70. The relative changes in health outcomes were captured by the time-specific coefficients. The year 2001 was set as a baseline for comparison with the following years' health outcomes. For number of health conditions, the base year was 2003 , as this health variable was not collected before 2003. For example, if a health outcome in 2015 was better (or worse) than in the baseline of 2001, then the coefficient of year dummy of 2015 was positive (or negative). The estimated changes of health and economic outcomes over time were illustrated in the graphs in coming sections.

${ }^{1}$ Adjusting household incomes: equivalence scales (oecd.org) 


\section{Results}

\subsection{Who are older employed people?}

Table 2 describes the socio-economic characteristics of the older population by their working status in 2001 and 2015. On average, employed people were about five years younger than their non-employed counterparts. The age gap is quite stable across 2001 and 2015, although the average age incrementally increased over time for both the employed and non-employed older population. There were more males in the older employed group in both years.

Employed older adults were more educated than their non-employed counterparts, particularly in 2015. They were more likely to be Australian born, and less likely to be Aboriginal or non-English migrants. Although there were some changes in relative ethnic composition over time, the overall ethnic patterns did not change.

Table 2 also presents unadjusted health and economic outcomes by the working status. Older employed adults were healthier than those not employed in all health measures such as mental health, physical functioning, general health, number of health conditions, and self-assessed health measure. The health gap between the two groups persisted over the period. Older workers earned more, and had significantly higher superannuation and net financial assets than those who were not in the labour force. In 2001, on average, regular private income was almost 5 times higher among those who were employed as those who were not, and about 3 times higher if government supports such as pension and social welfare benefits are included. The employed group also had about $88 \%$ more in superannuation and $57 \%$ more in net financial assets than the non-employed group in 2001, the gaps narrowed in 2015 but remained large.

In summary, workers aged 50-70 were more likely to be younger, men, healthier, more educated, have higher income, net financial assets, and superannuation than the unemployed in the same age cohort.

Table 2: Descriptive summary, older population aged 50-70, 2001 vs. 2015 


\begin{tabular}{|c|c|c|c|c|}
\hline & \multicolumn{2}{|l|}{2001} & \multicolumn{2}{|l|}{2015} \\
\hline & Employed & Unemployed & Employed & Unemployed \\
\hline & Mean (SD) & Mean (SD) & Mean (SD) & Mean (SD) \\
\hline \multicolumn{5}{|l|}{ Worker characteristics } \\
\hline Age & $55.8(4.7)$ & $61.2(5.8)$ & $57.0(5.1)$ & $62.4(5.6)$ \\
\hline Gender (Male $=1)(\%$ of male $)$ & $56.6(49.6)$ & $40.6(49.1)$ & $53.7(49.9)$ & $39.3(48.9)$ \\
\hline Tertiary education (\% with tertiary education) & $51.2(50.0)$ & $33.9(47.3)$ & $68.7(46.4)$ & $47.4(49.9)$ \\
\hline \multicolumn{5}{|l|}{ Ethnicity (\%) } \\
\hline [1] Australian born & $69.1(46.2)$ & $60.5(48.9)$ & $69.7(46.0)$ & $63.0(48.3)$ \\
\hline [2] Aboriginal & $0.79(8.8)$ & $1.3(11.1)$ & $1.2(10.9)$ & $1.79(13.3)$ \\
\hline [3] English speaking migrants & $15.0(35.7)$ & $15.1(35.8)$ & $12.5(33.0)$ & $12.7(33.3)$ \\
\hline [4] Non-English speaking & $15.1(35.8)$ & $23.2(42.2)$ & $16.6(37.3)$ & $22.6(41.8)$ \\
\hline \multicolumn{5}{|l|}{ Health variables } \\
\hline Mental health (scaled 0-100) & $78.3(15.3)$ & $71.9(19.5)$ & $76.8(15.9)$ & $71.9(19.0)$ \\
\hline Physical functioning (scaled 0-100) & $83.7(19.3)$ & $66.6(26.6)$ & $84.3(18.8)$ & $68.4(26.6)$ \\
\hline General health (scaled 0-100) & $71.9(19.0)$ & $58.5(24.8)$ & $68.3(19.1)$ & $56.7(23.9)$ \\
\hline No of health condition $(1-15)^{\star}$ & $0.27(0.52)$ & $0.76(0.77)$ & $0.30(0.57)$ & $0.89(0.82)$ \\
\hline \multicolumn{5}{|l|}{ Self-assessed health (\%) } \\
\hline [1] Excellent & $13.0(33.7)$ & $7.3(26.1)$ & $8.2(27.3)$ & $4.2(20.1)$ \\
\hline [2] Very good & $41.3(49.2)$ & $22.2(41.6)$ & $34.7(47.6)$ & $20.9(40.7)$ \\
\hline [3] Good & $34.5(47.5)$ & $34.3(47.5)$ & $41.5(49.6)$ & $38.2(48.6)$ \\
\hline [4] Fair & $9.6(29.5)$ & $26.5(44.1)$ & $14.6(35.4)$ & $27.0(44.4)$ \\
\hline [5] Poor & $1.6(12.5)$ & $9.6(29.5)$ & $1.1(10.4)$ & $9.7(29.6)$ \\
\hline \multicolumn{5}{|l|}{ Economic variables } \\
\hline Regular private income & $45.2(48.7)$ & $8.8(18.1)$ & $55.0(60.3)$ & $12.2(26.6)$ \\
\hline Income from all sources & $46.0(48.4)$ & $14.8(16.7)$ & $56.0(59.8)$ & $20.0(25.0)$ \\
\hline Superannuation** & $184(241)$ & $98(214)$ & $269(384)$ & $209(443)$ \\
\hline Net financial assets ** & 312 (478) & 199 (396) & $391(667)$ & 331 (808) \\
\hline
\end{tabular}

Notes: All monetary variables were adjusted for the survey sampling weight, and discounted to 2002 price. The Economic outcome variables were in AU\$1,000. ${ }^{*}$ Data available from wave 3 onwards. ${ }^{*}$ Data were available in every four years since 2002.

\subsection{Labour market participation by the older population}

The workforce participation rate of older Australians aged 50-70 also increased steadily over the past 15 years commencing 2001 (Figure 1), from 49\% in 2001 to 59\% in 2015. Participation increased for both men and women. Although the workforce participation rate is considerably higher for men, the gender participation gap between men and women slightly decreased, 
from $17 \%$ in 2001 to $14 \%$ in 2015 . This rising participation implies that the policy aiming at encouraging older people to participate or to stay in the labour market longer has been a success.

\subsection{Little evidence of improvement in health of the older population}

The rise in the older workers' labour force participation signals success for policies aiming to increase labour supply. However, this raises the question of whether or not rising participation reflects improvement in health, given the mixed evidence to date we hypothesised that health profile of employed older workers may not have improved [H1]. In this subsection, we look into changes in health of the older population over the period to answer such question.

In Figure 2, we compared health outcomes of the following years with the base year 2001, adjusting for some key socioeconomic characteristics such as age, sex, ethnicity, education and equivalized household income. It shows that for the older population, there is a gradual decline in all health outcomes over the study period, except for physical functioning of the employed people has remained rather stable over the same period.

The estimates using equation (1) shows that comparing to the baseline in 2001, in 2015 the mental health of similar (in terms of age, sex, ethnicity, education and equivalized household income) employed people worsened by 0.1 standard deviations $(p<0.01)$. Their general health declined by 0.22 standard deviations $(p<0.01)$, and the number of health conditions increased slightly by 0.06 standard deviations $(p<0.01) .^{2}$ Only their physical functioning barely improved (statistically insignificant) from

the baseline health. For unemployed people, their health outcomes over the same period deteriorated faster than their employed counterpart's health outcomes. Unemployed people's mental health was 0.23 standard deviations lower $(p<0.01)$, physical functioning 0.1 standard deviations lower $(p<0.01)$, general health 0.3 standard deviations lower $(p<0.01)$, and number of health conditions 0.42 standard deviations higher $(p<0.01)$.

Overall, regardless of working status in most instances we observed health deterioration. However, employed people are clearly healthier than unemployed people, and their health outcomes have deteriorated more slowly than those of the unemployed over the same period.

\subsection{Widening health gaps}

In this subsection, we considered the health changes over time across older employed and unemployed people, and propose contributors to the widening gap. Though employed older adult's health has not improved over time, the health of the unemployed people has deteriorated faster. This has generated a widening health gap between the two groups, as proposed in Hypothesis 2 (Figure 2). This is also confirmed by a statistical test which shows that the interaction terms between the working status (1/0) and the time variable in the health prediction equation (1) are statistically significant (the test results would be available upon request). The health selection process may operate i.e. better health supports the unemployed returning to the labour market (Figure 3), while poorer health is found amongst employed people exited the workforce (Figure 4).

We observed widening health gaps between those who were working and those who were not, begging the question - what contributes to such a widening gap? To answer this question, we broke down the sample by employment transition into four groups: re-entering the workforce, remaining employed, exiting the workforce, and remaining unemployed. For people who are working in the current year, they either remained employed or became unemployed in the following year. For example, among 1,733 people aged 50-70 who were employed in 2001, 1,538 people stayed employed and 195 people became unemployed (exited the workforce) in 2002. For people who are unemployed in the current year, we tracked their employment status in the following year. They were either unemployed or returned to the workforce in the following year. For example, among 1,566 people aged 50-70 who were unemployed in 2001, 1,471 people remained non-employed and 95 people became employed in 2002. 
In Figure 3, we compared health outcomes by employment transition status. Figure 3 (and also Figure 4) was adjusted for age, sex, ethnicity, education, equivalized income per capita, and time effect using the random effect maximum likelihood estimator. It clearly shows that the "re-entering" group has better health outcomes than the "remain non-employed" (Figure 3). The health scores for physical functioning, mental health and general health of the re-entering people were considerably higher than the "remain unemployed" people, and they also have a significantly lower number of health conditions. Moreover, the health gap between these two groups has widened. Departure of the re-entering people, who have better health, from the unemployed group results in lowering health outcomes (general health, physical functioning and mental health) and increasing number of health conditions of the remaining unemployed people. This partly contributes to widening health gap between who were working and who were not.

In brief, the exit of the poorer health workers from the employed group and the re-joining of healthier older adults to the workforce is a health selection effect that increases the health gap between workers and those who were not working. The movement into and out of the labour market by older people with differing health status has contributed to the widening health gap.

\subsection{Widening health gaps accompanied by widening economic outcomes}

The widening health gap raises a question of what it means for economic outcomes in the short term and in the long term, and for socio-economic inequality. We had hypothesized that the widening health gap is accompanied by widening income, superannuation, and net financial asset gaps. In this subsection, we considered these economic outcomes: incomes without government support, incomes with government support, superannuation, and household net financial assets. ${ }^{3}$

\section{a. Short-term economic outcome: Income}

Income is measured for a financial year. As shown in Figure 5, the widening health gap (as seen in Figure 2) is accompanied by widening income gap. There is strong evidence of widening income gap between those who were working and who were not over the considered period. When considering income with government support provided to the unemployedthe gap becomes smaller, but is still significantly large (the right panel, Figure 5).

\section{b. Long-term economic outcomes: superannuation and net financial assets}

Over time, working and savings from incomes helps build up superannuation and net financial assets for older workers. Prolonged employment and higher incomes contribute to larger cumulative savings, superannuation and financial assets [30, 31]. As we wish to examine the association between the economic outcomes and health in the wage labour market context, we exclude other economic outcomes e.g. wealth which is mainly generated from saving of labour market earnings and from investment profits (business and property investment). The latter are not related to the wage labour market activities, thus we use net financial assets which exclude business and property assets and related debts. The net financial assets capture superannuation, savings on bank accounts, bank account balances, cash and equity investments, trust funds and life insurance. Consequently, the household net financial assets and superannuation are better measures of long term accumulated economic outcomes of the wage labour market participation.

Figure 6 shows how superannuation and household net financial assets change over the period 2002 to 2014 by employment status. It shows that employment boosted superannuation and net financial assets, generating a widening gap in both superannuation and net financial assets between those who were working and who were not. However, we observed large standard deviations in the changes of superannuation and the financial assets; indicative of the economic outcomes are heterogeneous within each group. We will discuss in more details in the following section.

Page $10 / 25$ 


\subsection{Widening health gaps is also accompanied by increasing economic inequality}

\section{a. Within and between group comparisons}

The heterogeneous superannuation and net financial assets indicates that each employment status group is composed of diverse individuals. For example, in the unemployed group, some people were healthy and wealthy but chose to retire early (not working). In contrast, some people were unemployed because they were unhealthy. The sample stratification by wealth distribution will provide more insight into the heterogeneity of the sample.

Within each group by employment status, we stratified the samples into the top $20 \%$ richest and the remaining $80 \%$ (also called the bottom $80 \%$ in this paper) based on net wealth distribution. We then estimated superannuation, net financial assets, and some key health measures (see Table 3 below). Among the unemployed group, the top $20 \%$ of the wealth distribution had very high net financial assets and superannuation relative to the remaining (80\%) group. Their net financial assets and superannuation were very close to those of the top $20 \%$ wealthiest of the employed people. Their superannuation was even the highest $(\$ 578,000)$ among the four subgroups. This group was obviously healthy and wealthy, but chose to retire early because they had sufficient sources of income from superannuation and financial assets. This group also had much better health outcomes than the rest of the unemployed group. On the contrary, the remaining $80 \%$ of the unemployed group had considerably lower net financial assets, low superannuation, and poor health outcomes.

Table 3: Health, superannuation, and financial assets by working status, aged 50-70

\begin{tabular}{|lllll|}
\hline & Employed & \multicolumn{2}{l|}{ Unemployed } \\
\hline & Top 20\% & Remaining 80\% & Top 20\% & Remaining 80\% \\
\hline Net financial assets & 1,011 & 206 & 1,012 & 106 \\
\hline (Std Dev) & $(1,152)$ & $(194)$ & $(1,113)$ & $(146)$ \\
\hline Superannuation & 572 & 155 & 578 & 67 \\
\hline (Std Dev) & $(599)$ & $(159)$ & $(666)$ & $(114)$ \\
\hline Physical functioning & 86.9 & 83.5 & 80.0 & 65.0 \\
\hline (Std Dev) & $(17.0)$ & $(19.1)$ & $(20.2)$ & $(27.0)$ \\
\hline Mental health & 80.6 & 77.1 & 78.9 & 70.0 \\
\hline (Std Dev) & $(12.7)$ & $(15.6)$ & $(16.1)$ & $(19.6)$ \\
\hline General health & 73.0 & 69.1 & 66.8 & 54.5 \\
\hline (SD) & $(18.0)$ & $(19.4)$ & $(21.2)$ & $(24.6)$ \\
\hline Number of health conditions & 0.37 & 0.50 & 0.85 & 1.93 \\
\hline (SD) & $(0.91)$ & $(1.18)$ & $(1.66)$ & $(2.34)$ \\
\hline
\end{tabular}

Note: The estimates were adjusted for sample weight, but were not adjusted for age, sex, ethnicity, and education. Standard deviations are in parentheses.

Therefore, the top $20 \%$ of unemployed were 'wealthy and healthy'. This subgroup had about 6 times more net wealth as that of the remaining $80 \%$ of the unemployed, 10 times the net financial assets, and 9 times the superannuation of the remaining $80 \%$ of the unemployed. For this healthy and wealthy subgroup, irrespective of their health, their wealth protected them. The remaining $80 \%$ of the unemployed were 'un-wealthy and unhealthy'. 
The top $20 \%$ of employed workers is similar to the top $20 \%$ of the unemployed in terms of health, net financial assets and superannuation. The only difference is that they chose to remain in the labour market. In contrast, the remaining $80 \%$ of the employed were less wealthy but they were relatively healthy. Their health outcomes were close to those of the top $20 \%$ of both the employed and unemployed groups. Their better health hence enabled them to remain in the labour market.

Figure 7 considered how superannuation changed over the period using 2002 as the baseline. The top left panel compares the top $20 \%$ wealthiest and the remaining $80 \%$ of the employed group. It shows a widening gap in superannuation, though the remaining $80 \%$ subgroup's superannuation has improved over time. The gap in superannuation between the top $20 \%$ and bottom $80 \%$ of the unemployed group has grown faster than the gap between the top and bottom of the employed group. This again confirms that the wealthy and healthy within the unemployed chose to retire early or chose not to work in the wage labour market because they had sufficient superannuation and other sources of income.

The bottom right panel compares superannuation changes between all employed workers and the remaining $80 \%$ of the unemployed group (the un-wealthy and unhealthy). The bottom left panel compares superannuation changes over time between the "unhealthy and un-wealthy" in the unemployed group and the "healthy and un-wealthy" in the employed group. This comparison best demonstrates the role of health in employment and cumulative saving/superannuation. It is likely that better health promotes employment participation among older people which in turn helps build up superannuation. The gap in superannuation between these two subgroups has widened over the period.

In Figure 8, we repeated the same analysis for net financial assets as for superannuation in Figure 7 and found a similar pattern. The gap in net financial assets has widened over time within each working status group (top two panels of Figure 8), and across groups (bottom two panels). Remaining employed due to better health helps build up financial assets faster than being unemployed (bottom left panel). The unhealthy and un-wealthy unemployed group face double burdens of poor health, and low and little improvement in superannuation and net financial assets.

\section{b. The un-wealthy and unhealthy group left behind - worsening health and economic inequality}

The 'left-behind'group (the un-wealthy and unhealthy), the remaining $80 \%$ of the unemployed is facing a growing health and economic gap. They endure poor health and have no opportunity to improve their income. Below we have provided further evidence that the un-wealthy and unhealthy group has declining resources to improve their health and wellbeing.

\section{Within the unemployed group comparison}

In Figure 9, we compared four economic outcome changes between the top 20\% wealthiest and the remaining $80 \%$ (the leftbehind) of the unemployed. The economic outcomes are regular private income, total income (regular private income and government supports such as pension and social welfare benefit), accumulated superannuation, and household net financial assets.

Compared with the baseline year 2002, the wealthiest of the unemployed group received more than $\$ 20 \mathrm{k}$ income in 2014, while the left behind group's income changed very modestly. The addition of the government support made a small change to the total income over the period, of just less than $\$ 5 \mathrm{k}$. In terms of superannuation and net financial assets, the left behind group own relatively small amounts of superannuation and financial assets in relation to the wealthiest, and the gap between these two groups has become very large (bottom panel of Figure 9).

The un-wealthy and unhealthy group is falling behind in all our economic outcome measures. This resulted in rising health and economic inequality. Figure 10 compared the economic outcome changes over time for the un-wealthy and unhealthy group with those of all employed older workers. It again shows widening gaps in income, superannuation and net financial assets. The employed group's income, superannuation and net financial assets improved over time at a greater rate than those of the left-behind group.

Page $12 / 25$ 
Briefly, considering all the comparisons we have made so far, the common finding is that those who had poor health and were (un)wealthy are falling behind in all economic outcome measures such as income, income with the government support, superannuation and net financial assets.

${ }^{2}$ We standardized (by its mean and standard deviation) all health variables in order to put the health outcomes in the same range figures for convenient comparison.

${ }^{3}$ Note that we do not add up superannuation or net financial assets with the income as income is measured for a financial year, while superannuation or net financial assets are stock and accumulated over time.

\section{Conclusion, Limitations And Discussion}

\subsection{Conclusion}

Thanks to improvements in living standards and healthcare, Australians born in recent years can live about 33 years longer compared with those born at the Federation on 1901 [1, 15]. Longer life expectancy is assumed to equate with being healthier, which supports the policies to extend working life and retirement age.

This paper has examined the interplay between the older population's health and employment participation over the past fifteen years. It showed that Australia's participation policy has been successful; the older labour force increased by ten percent during the past 15 years. However, we found little evidence of improvement in health outcomes of this older population regardless of their working status. In most instances, we observed health deterioration over the period. Overall, older healthier people remained in employment or returned to the labour market if they were previously unemployed, while those with poorer health remained in unemployment or exited the labour market if they were previously employed. The health gap between who those were working and those who were not has been widening. The increasing rates of people with relatively better health returning to the labour market, and increasing rates of people with relatively poorer health exiting the labour market, operates as a dynamic process of health selection which has contributed to the widening health gap between the employed and the unemployed people.

The widening health gap between those who were working and those who were not is accompanied by rising economic inequality within the older population. Income, net financial assets, superannuation, and health interact. Better health enables people to remain or return to the labour market, while poor health keeps them unemployed or pushes them out of the labour market $[6,7]$. The financial benefits of employment assist older workers maintain their good health or impedes health deterioration due to their ability to pay to pay for healthcare [5]. Net financial assets and superannuation protects the older people's health. Thus, older people who were healthy and wealthy may choose not to work or retire early because they have sufficient accumulated assets and superannuation.

In contrast, older people with poor health as well as limited assets and superannuation required income and employment for financial reasons, but their poor health prevented them from labour market participation. Employment history matters in later life savings and income [30,32]. Unemployment combined with low income, low superannuation and low financial assets has created widening gaps in health and economic outcomes between the disadvantaged people with the rest [20, 28]. These factors drive the rising health and economic inequality among older people in Australia. Without good health and employment, the un-wealthy and unhealthy older people were vulnerable and need government support to help them acquire health improvements, financial support, and employment opportunities so that they can resist the downward spiral across these three dimensions.

\subsection{Limitations and consolidation}

The current analysis does not aim to estimate causal relationships but instead examines the association between health and employment participation. One may argue that linking health differentials by work status may face endogeneity biases due to 
reverse causality. To address this and strengthen our policy discussion we we analysed older workers' labour market participation using their prior health measures ( $1^{\text {st }}$ lags) as predictors.

Using a longitudinal logistic model, all prior health measures strongly affected the probability of labour market participation for 50-70 year olds, thereby supporting the occurrence health selection into the labour market (Table 4). The estimates show that prior better health measures are good predictors of being employed for older workers. More specifically, the negative coefficients e.g., having fair or poor health $(y=1)$ or having a health restriction $(y=1)$ will reduce the likelihood of being employed, while the positive coefficients e.g. mental health, general health or physical functioning means better health (in these health measures) and willincrease the likelihood of being employed.

Table 4: Health conditions and working status, Longitudinal (RE) Logistic model, aged 50-70

\begin{tabular}{|c|c|c|c|c|c|c|}
\hline & $(1)$ & $(2)$ & (3) & (4) & (5) & $(6)$ \\
\hline \multirow[t]{2}{*}{ Fair \& poor health (lag) (yes=1) } & 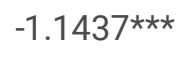 & $-0.9717 \star \star \star$ & 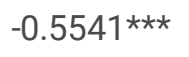 & & & \\
\hline & $(0.0832)$ & $(0.0854)$ & $(0.1000)$ & & & \\
\hline \multirow[t]{2}{*}{ Mental health (lag) } & & $0.0199 * \star \star$ & $0.0141^{\star \star \star}$ & $0.0141 * \star \star$ & $0.0162^{\star \star \star}$ & $0.0170 \star \star \star *$ \\
\hline & & $(0.0022)$ & $(0.0023)$ & $(0.0023)$ & $(0.0022)$ & $(0.0022)$ \\
\hline \multirow[t]{2}{*}{ Gen health (lag) } & & & $0.0197^{\star \star \star}$ & $0.0263^{\star \star \star}$ & & \\
\hline & & & $(0.0025)$ & $(0.0021)$ & & \\
\hline Health restriction (lag) & & & & & $-1.5091^{\star \star \star}$ & \\
\hline$($ Yes=1) & & & & & $(0.0791)$ & \\
\hline Physical functioning & & & & & $0.0188^{* \star \star}$ & $0.0212^{\star \star \star}$ \\
\hline (lag) & & & & & $(0.0018)$ & $(0.0018)$ \\
\hline Long term health & & & & & & $-0.9517^{* \star *}$ \\
\hline Condition (lag) (yes=1) & & & & & & $(0.0682)$ \\
\hline \multirow[t]{2}{*}{ Constant } & $31.52 * \star \star$ & $30.25^{\star \star \star}$ & 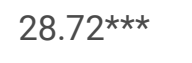 & $28.28 * \star \star$ & 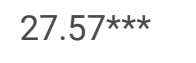 & 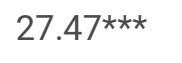 \\
\hline & $(0.7043)$ & $(0.7113)$ & $(0.7218)$ & $(0.7102)$ & $(0.7182)$ & $(0.7189)$ \\
\hline Prob>chi2 & 0.0000 & 0.0000 & 0.0000 & 0.0000 & 0.0000 & 0.0000 \\
\hline Observations & 38,512 & 38,360 & 37,992 & 38,401 & 38,421 & 38,434 \\
\hline No of individuals & 6,928 & 6,923 & 6,910 & 6,915 & 6,920 & 6,920 \\
\hline
\end{tabular}

Note: Standard errors in parentheses, ${ }^{* *} p<0.01,{ }^{* *} p<0.05,{ }^{*} p<0.1$. Models also controlled for lags of net financial assets, financial distress, non-wage income, age, unpaid time, marital status, gender, education level, ethnicity, state, and year dummies.

Moreover, an assessment that health did not improve (after adjusting for many factors, including equivalised income per capita) for workers and non-workers may be problematic due to the risk of endogeneity from 2-way causality between income and health. When we trialled models using prior equivalised income per capita, the estimates did not change the health trend over time. (The estimates are available upon request).

\subsection{Discussion}

In this paper, we have provided new evidence to support a potential policy debate. First, we showed, in the context of increasing longevity, that labour force health is deteriorating. Policies that promote jobs and businesses to accommodate the diverse 
health needs and capabilities of their older workforce are required. Second, rising health inequality between the employed and unemployed is accompanied by the rising economic inequality in incomes, cumulative financial assets and superannuation. As we showed in this analysis, improving the older population's health is one of the keys to promoting employment participation as well as reducing the need for financial support and thus mitigating public financial pressure. Third, some older unemployed who were healthy could choose not to work due to their high wealth, assets and superannuation, leaving the remaining unemployed with low incomes, low assets and low superannuation, and poor health. Their poor health restricted them from employment and earnings. Policy aiming at promoting employment participation for the older population should focus on this "left-behind" group who need both health and financial/income support.

Working longer is a gain for both individual workers and society in the context of ageing population in Australia. Employment is good for both health and later life savings and income [20,32,33]. Improving older workers' participation in the labour market longer would support national productivity, respond to labour shortages, and reduce public finance pressure currently and in the foreseen future. However, good health is fundamental to employment participation and productivity $[16,17,18]$. Policy priorities should focus on preventing ill-health in tandem with extending working age and promoting participation. The current policy does not address the former.

Policy should target the most vulnerable people in order to help them both improve health and re-participate in the workforce. It could also provide budget savings by reducing social welfare payments, solve labour shortages, increase labour productivity, makes public health savings, and more importantly improve older people's access to better health and wellbeing.

The current monolithic policy does not address the health needs of most older workers. The current pension age eligibility of 67 in Australia is realistic for some, but highly problematic for many other older workers, particularly for those who work in physical demanding jobs. While increasing longevity enables people to work longer in principle, not all older people are able to work as long as the current policy wishes e.g. working till aged 67 (by 2023), five days per week, and eight hours per day. The older population' work capacity depends on their health as we indicated in this paper.

\section{Declarations}

\section{- Ethical Approval and Consent to participate:}

This study uses secondary data from Household Income and Labour Dynamics in Australia (HILDA), and we have obtained the ethical approval from the Australian National University Ethic Committee

\section{- Consent for publication}

Not applicable. There is no restriction on publication of the research outcomes from our approved research project.

\section{- Availability of data and materials}

We are not allowed to share the unit-record data, however, the dataset is accessible to anyone with approval from HILDA.

\section{- Competing interests}

The authors declare that there is no conflict of interest in conducting this research.

\section{-Funding}

This paper is part of a larger project supported by an Australian Research Council Linkage Grant LP160100467.

\section{- Authors' contributions}

Huong Dinh and Lyndall Strazdins initiated the ideas, direction of the paper and policy discussion, Lyndall helps sharp the policy discussion and background. 
Tinh Doan and Thuy Do developed method and data analysis, Tinh drafted up the paper.

Amelia Yazidjoglou helps with literature review

Cathy Banwell supports writing, editing and policy discussion.

\section{-Acknowledgements}

This paper uses unit record data from the Household, Income and Labour Dynamics in Australia (HILDA) Survey 2005-2016. The HILDA Project was initiated and is funded by the Australian Government Department of Social Services (DSS) and is managed by the Melbourne Institute of Applied Economic and Social Research (Melbourne Institute). The findings and views reported in this paper, however, are those of the authors and should not be attributed to either DSS or the Melbourne Institute. We thank Melanie Pescud for her helpful comments and inputs into the paper.

\section{References}

1. Productivity Commission and An Ageing Australia, Preparing for the Future. Canberra: Commision Research Paper Overview, 2013.

2. ABS (2006). National Health Survey 2004-05: Summay of Results, Australian Bureau of Statistics, Canberra. Available at https://www.ausstats.abs.gov.au/ausstats/subscriber.nsf/0/3B1917236618A042CA25711F00185526/\$File/43640_200405.pdf

3. ABS (2015). National health survey 2014 - 15. Australian Bureau of Statistics, Canberra. Available at https://www.abs.gov.au/AUSSTATS/abs@.nsf/Lookup/4364.0.55.001Main+Features100012014-15?0penDocument

4. Mein, G., et al., Predictors of early retirement in British civil servants. Age and ageing, 2000. 29(6): p. 529-536.

5. Ross, C.E. and J. Mirowsky, Does employment affect health? Journal of Health and social Behavior, 1995: p. $230-243$.

6. Robroek, S.J., et al., Poor health, unhealthy behaviors, and unfavorable work characteristics influence pathways of exit from paid employment among older workers in Europe: a four year follow-up study. Scandinavian journal of work, environment \& health, 2013: p. 125-133.

7. Virtanen, M., et al., Extending employment beyond the pensionable age: a cohort study of the influence of chronic diseases, health risk factors, and working conditions. PloS one, 2014. 9(2): p. e88695.

8. Magee, C.A., P. Caputi, and J.K. Lee, Distinct longitudinal patterns of absenteeism and their antecedents in full-time Australian employees. Journal of occupational health psychology, 2016. 21(1): p. 24.

9. Summerfield, M., HILDA User Manual - Release 9, Melbourne Institute of Applied Economics and Social Reserach, Editor. 2011, University of Melbourne.

10. Ware, J.E., et al., SF_36 Health Survey Manual and Interpretation Guide. Quality Metric Inc. 2000, Lincoln RI.

11. Ware, J.E., Jr., et al., Comparison of methods for the scoring and statistical analysis of SF-36 health profile and summary measures: summary of results from the Medical Outcomes Study. Medical Care, 1995. 33(4 Suppl): p. As264-79.

12. Wooldridge, J.M., Cluster-Sample Methods in Applied Econometrics. The American Economic Review, 2003. 93(2): p. 133138.

13. Wooldridge, J.M., Fixed-Effects and Related Estimators for Correlated Random-Coefficient and Treatment-Effect Panel Data Models. The Review of Economics and Statistics, 2005. 87(2): p. 385-390.

14. Plümper, T. and V.E. Troeger, Efficient estimation of time-invariant and rarely changing variables in finite sample panel analyses with unit fixed effects. Political Analysis, 2007. 15(2): p. 124-139.

15. ABS. Life expectancy improvements in Australia over the last 125 years. Australian Bureau of Statistics, 2017. Canberra, Australia.

16. Noone, J., Knox, A., O'Loughlin, K., McNamara, M., Bohle, P., and Mackey, M. An Analysis of Factors Associated With Older Workers' Employment Participation and Preferences in Australia. Frontier in Psychology, 2018. 9(2524), p.1-16. 
17. Schofield, D., Shrestha, R., \& Cunich, M., et al. (2015). Lost productive life years caused by chronic conditions in Australians aged 45-64 years, 2010-2030. Med. J. Aust, 203-260.

18. van Rijn, R., Robroek, J., Brouwer, S., \& Burdorf, A. (2014). Influence of poor health on exit from paid employment: a systematic review. Occup. Environ. Med. 71, 295-301.

19. Australian Institute of Health and Welfare. (2017). Health-adjusted life expectancy in Australia: expected years lived in full health 2011. Canberra: AlHW.

20. Bosworth, B., Burtless, G., \& Zhang, B. (2016). Later retirement, inequality in old age, and the growing gap in longevity between rich and poor. (87).

21. de Wind, A., Scharn, M., Geuskens, . A., van der Beek, J., \& Boot, R. (2018). Predictors of working beyond retirement in older workers with and without a chronic disease-results from data linkage of Dutch questionnaire and registry data. BMC Public Health, 18(1), 265.

22. Dupre, E., George, K., Liu, G., \& Peterson, D. (2012). The cumulative effect of unemployment on risks for acute myocardial infarction. Archives of internal medicine, 172(22), 1731-1737.

23. Knox, G. (2003). Retirement intentions of mature age workers. Paper presented at the Australian Social Policy Conference.

24. Perenboom, J., van Herten, M., Boshuizen, C., \& van Den Bos, A. (2005). Life expectancy without chronic morbidity: trends in gender and socioeconomic disparities. Public Health Reports, 120(1), 46-54.

25. Robine, M., Saito, Y., \& Jagger, C. (2009). The relationship between longevity and healthy life expectancy. Quality in Ageing Older Adults, 10(2), 5-14.

26. Rumball-Smith, J., Barthold, D., Nandi, A., \& Heymann, J. (2014). Diabetes associated with early labor-force exit: a comparison of sixteen high-income countries. Health affairs,33(1), 110-115.

27. Taskila, T., Shreeve, V., Laghini, M., \& Bevan, S. (2015). Living long, working well: Supporting older workers with health conditions to remain active at work. London: The Work Foundation

28. Visser, M., Gesthuizen, M., Kraaykamp, G., \& Wolbers, J. (2016). Inequality among Older Workers in the Netherlands: A Life Course and Social Stratification Perspective on Early Retirement. European Sociological Review, 32(3), 370-382.

29. Cahill, T., Bowes, P., Duncan, E., Drye, E., et al. (2011). Risk Stratification by Cardiac Biomarkers following Emergency Gastrointestinal Surgery. International Scholarly Research Network ISRN Vascular Medicine, 2011, 1-5.

30. Jun Feng, J., Gerrans, P., Moulang, C., Whiteside, N \& Strydom, M. (2019). Why Women Have Lower Retirement Savings: The Australian Case. Feminist Economics, 25(1), 145-173.

31. Bingham, C. (2003). Impact of private saving and longer careers on retirement incomes. Retirement and Income Modelling Unit Department of the Treasury. Paper presented to the Eleventh Colloquium of Superannuation Researchers, University of New South Wales, 7 \& 8 July 2003.

32. Sefton, T., Evandrou, M., Falkingham, J., \& Vlachantoni, A. (2011). The relationship between women's work histories and incomes in later life in the UK, US and West Germany. Journal of European Social Policy, 21(1), 20-36

33. Karsten, P., Klaus, M. (2009). Unemployment impairs mental health: meta-analyses. Journal of Vocational Behaviour. 74, 264-282.

\section{Figures}




$$
\text { - - Overall Men Women }
$$

70.0
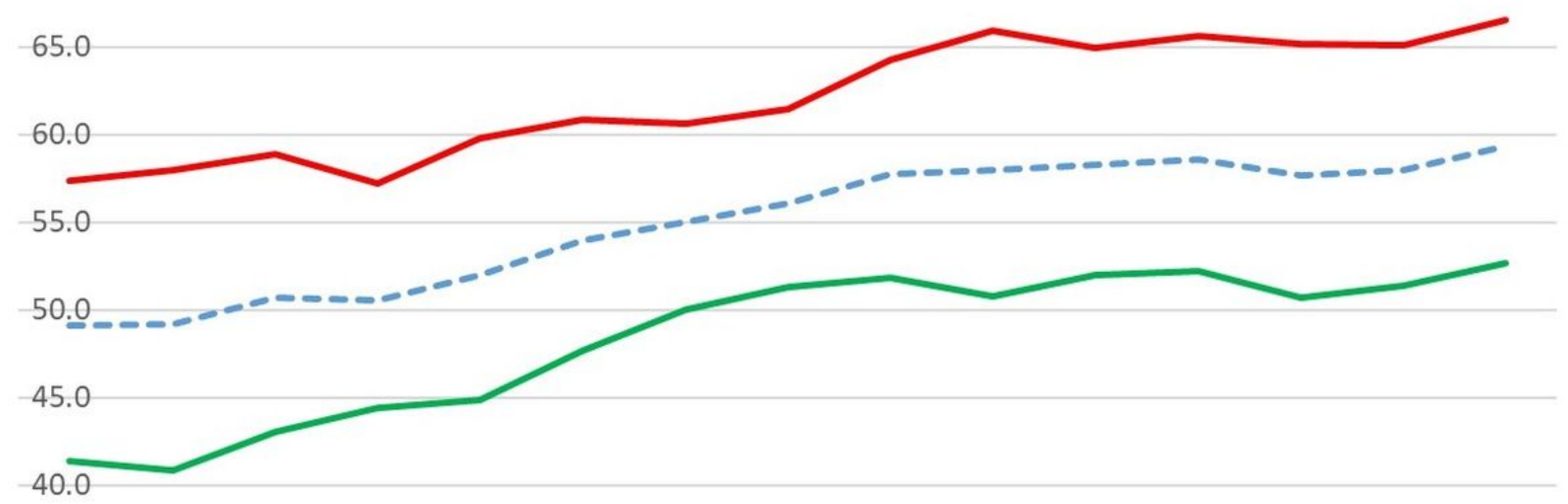

35.0

30.0

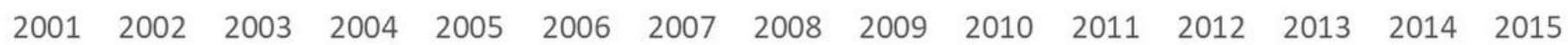

\section{Figure 1}

Labour market participation rate over time by gender, aged 50-70 Source: Authors' estimation from HILDA 2001-2015 

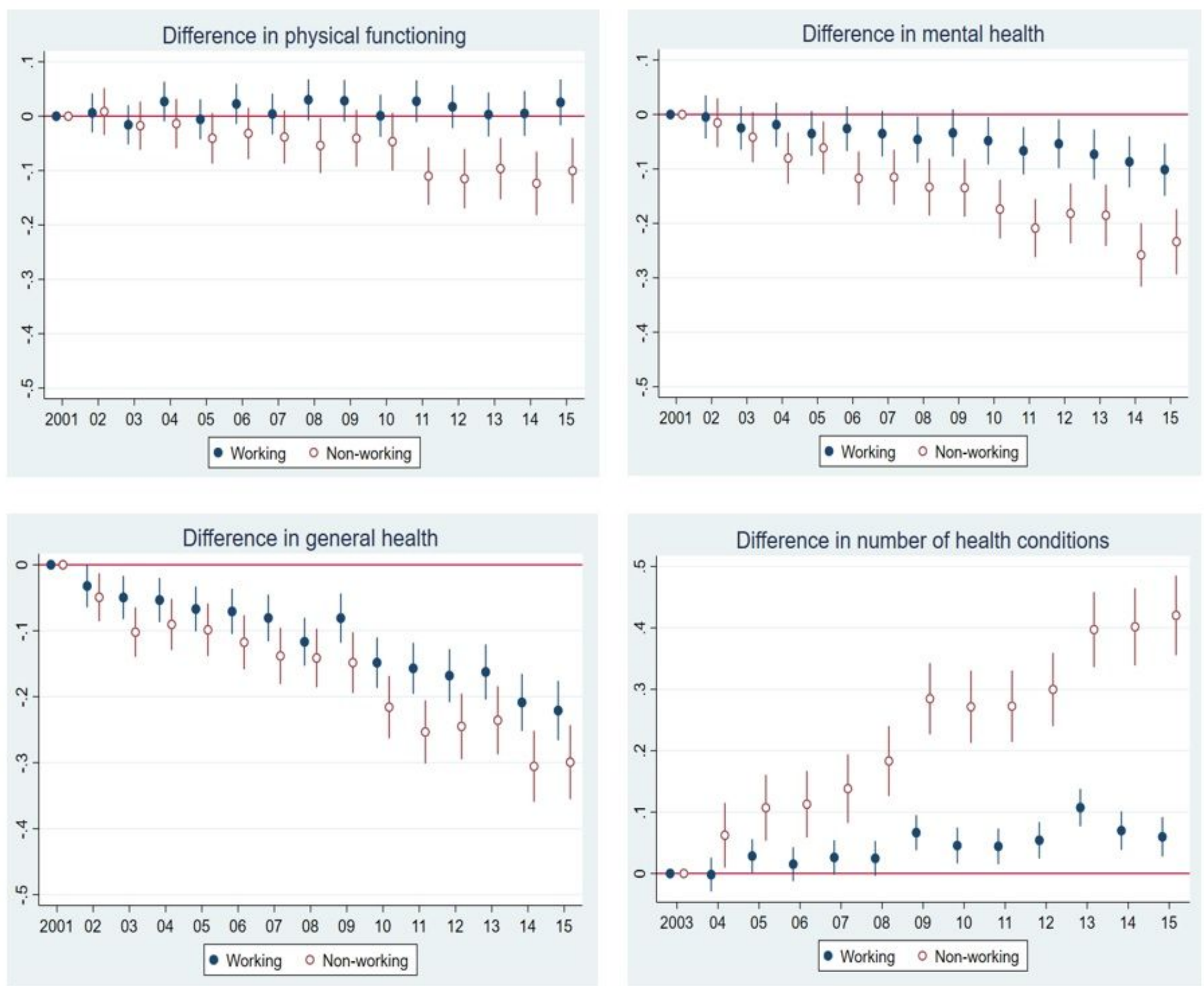

Figure 2

Relative change of health outcomes to the baseline. Notes: 2001 is the start year that the health data are available, otherwise indicated. All the health scores/measures were standardised by its mean and standard deviation in the 50-70 sample in order to put health outcomes in the same range figures for convenient comparison. All health outcomes were adjusted for age, gender, ethnicity, education and income. 

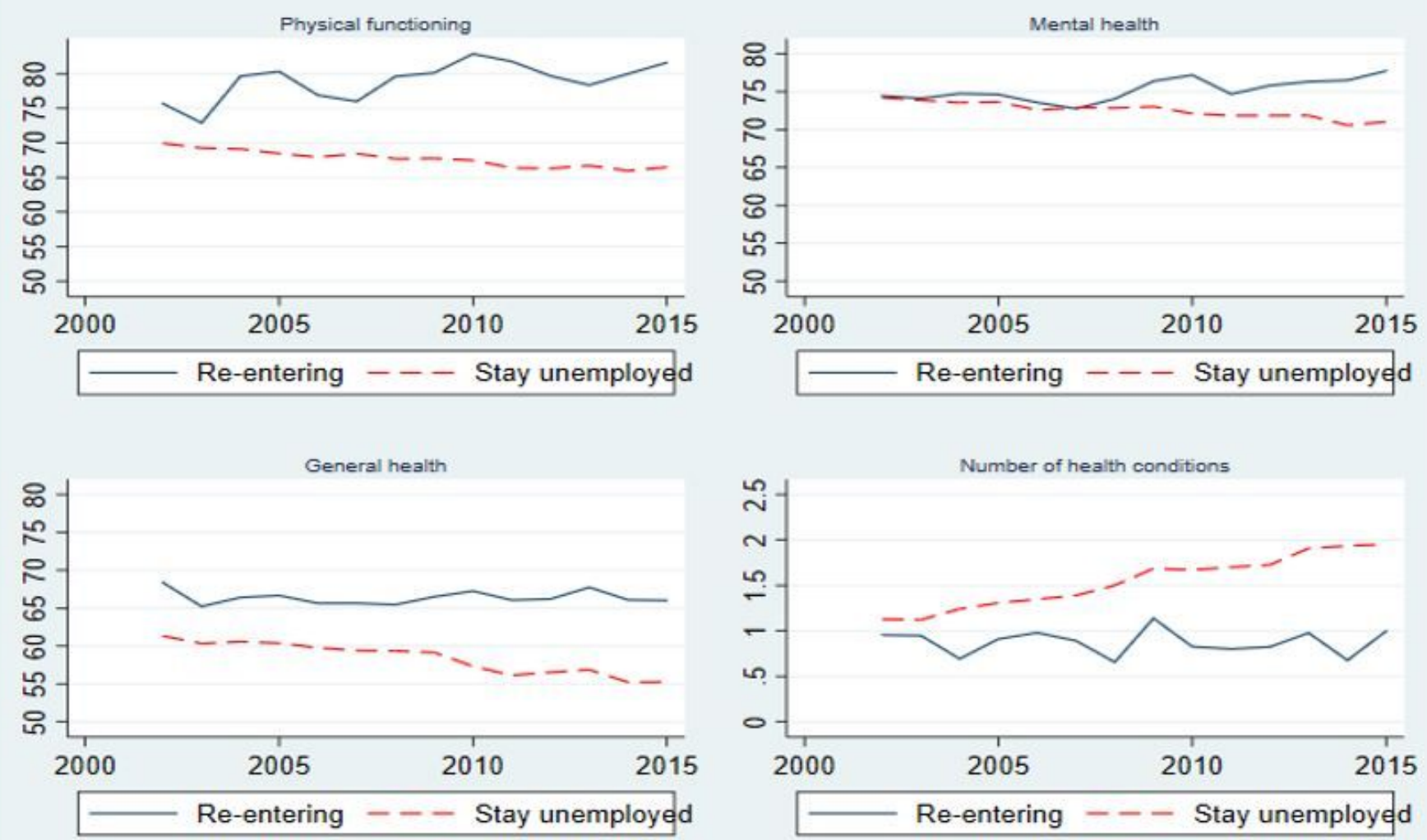

\section{Figure 3}

Health of the re-entering workers vs. the 'stay unemployed' population, aged 50-70 Note: Estimates were adjusted for age, sex, ethnicity, education, equivalized income per capita, and time effect using the random effect maximum likelihood estimator. 

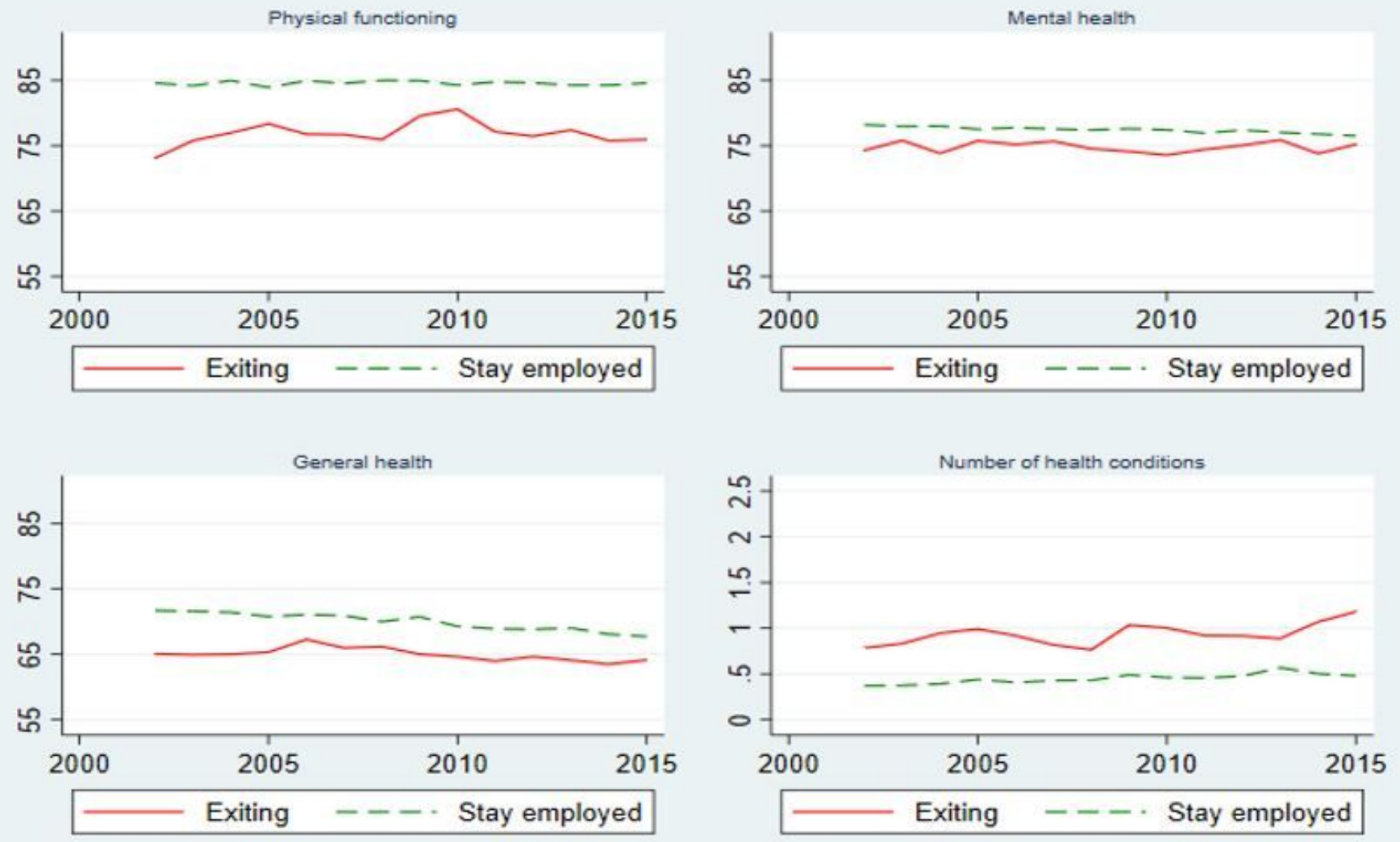

\section{Figure 4}

Health of the exiting workers vs. to the 'stay employed' population, aged 50-70 Note: Estimates were adjusted for age, sex, ethnicity, education, equivalized income per capita, and time effect using the random effect maximum likelihood estimator.

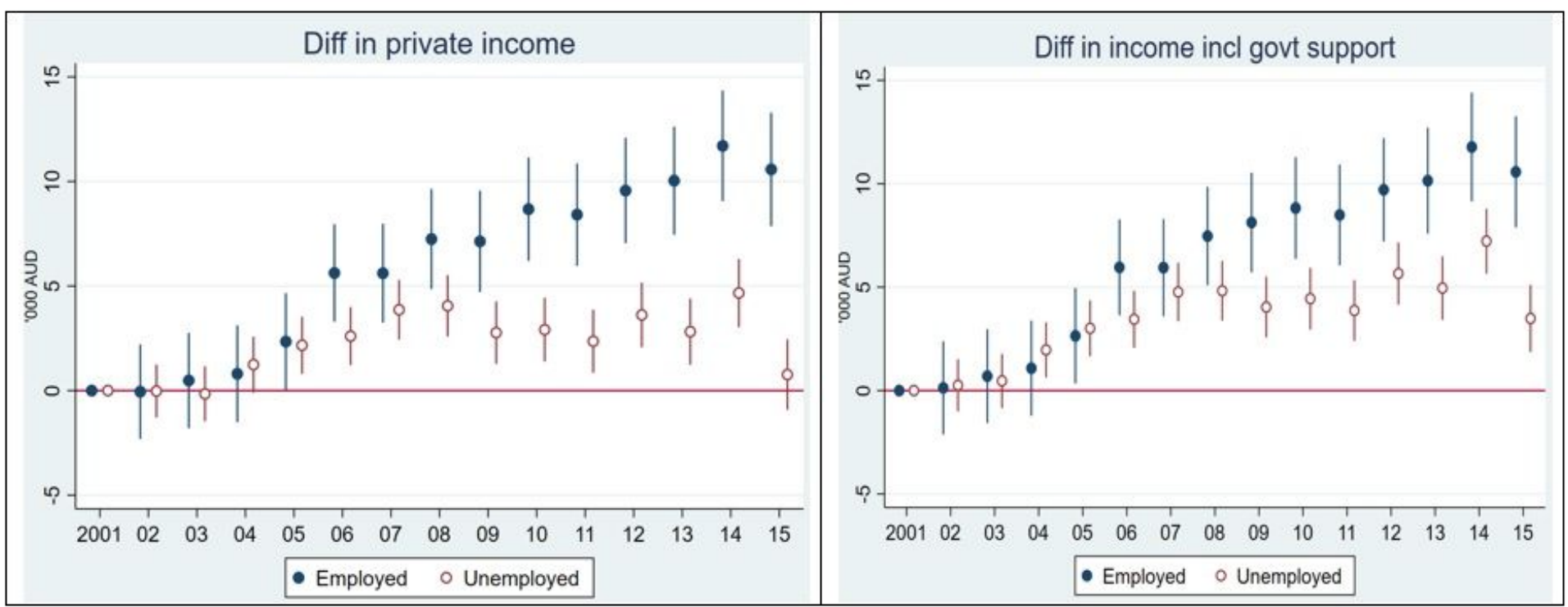

\section{Figure 5}

Relative change of income over time to the reference year 2001 Notes: 2001 is set as the base year. All monetary variables are measured in AU\$1,000 and discounted to 2002 price level. Estimates were adjusted for age, sex, ethnicity, education, and time effect. 

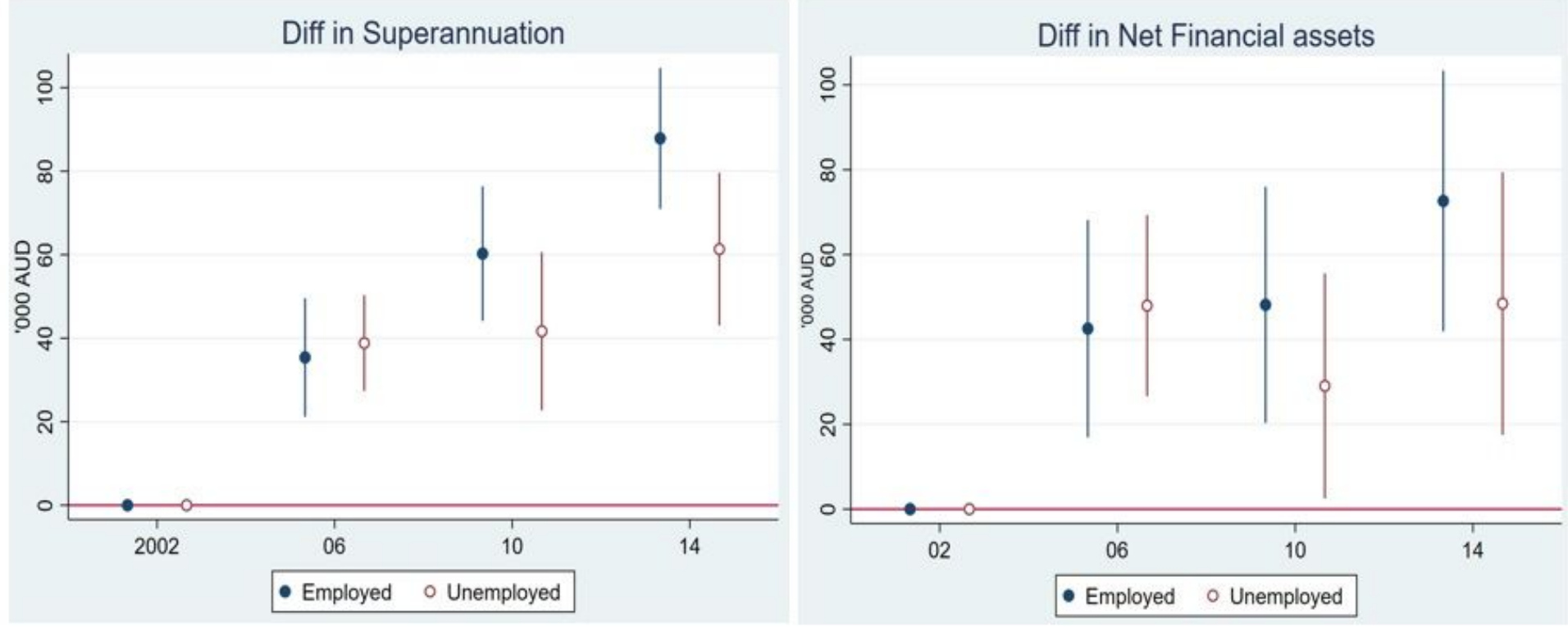

\section{Figure 6}

Relative change of superannuation and household net financial assets. Notes: 2002 is set as the base year. All monetary variables are measured in AU\$1,000 and discounted to 2002 price level. Estimates were adjusted for age, sex, ethnicity, education, and time effect.
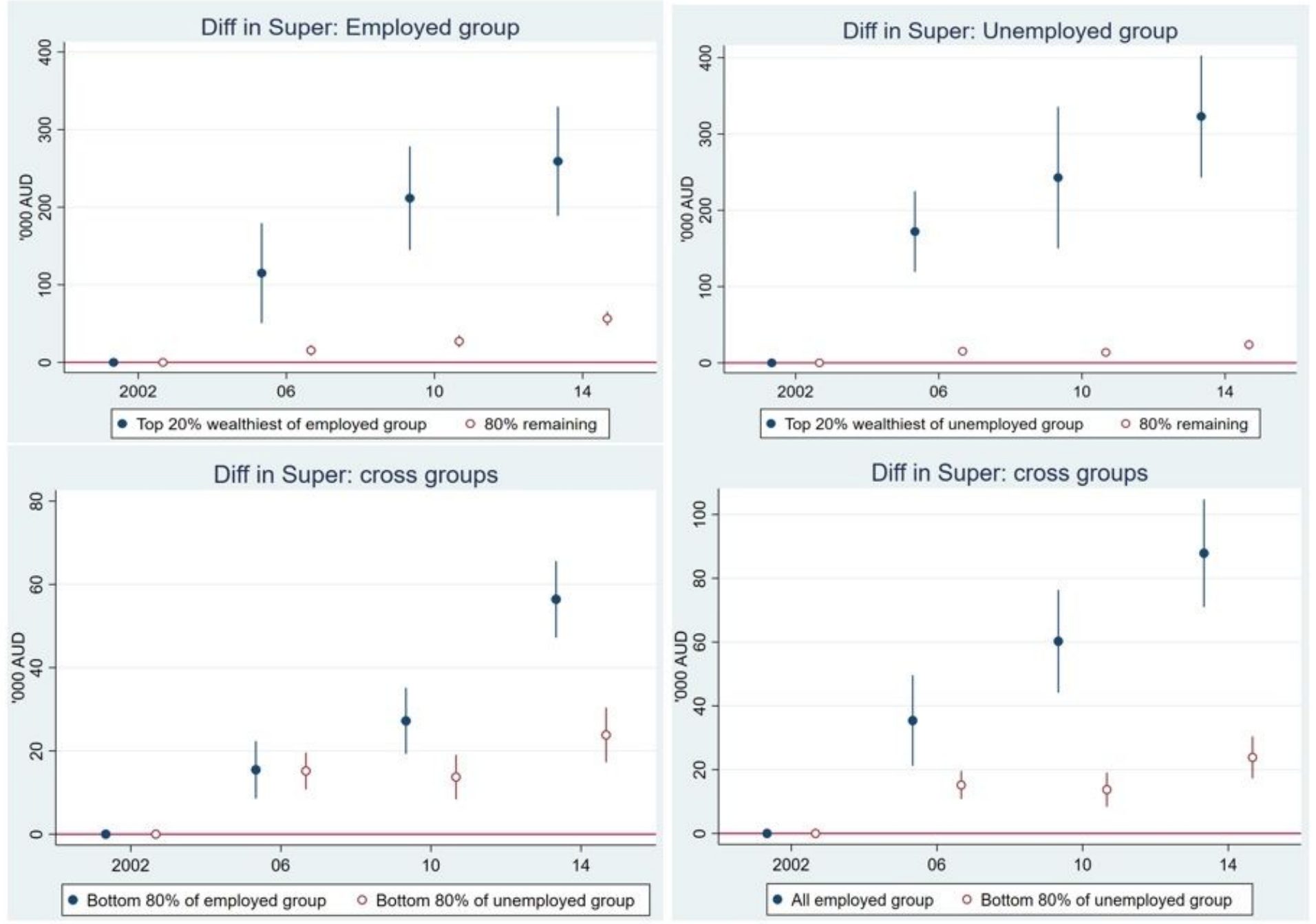
Figure 7

Relative change of superannuation to the reference year 2002 Notes: Estimates were adjusted for age, sex, ethnicity, education, and time effect. The reference year is the first year that the data are available. Superannuation was first collected in 2002 , and measured in AU\$1,000 and discounted to 2002 price level.
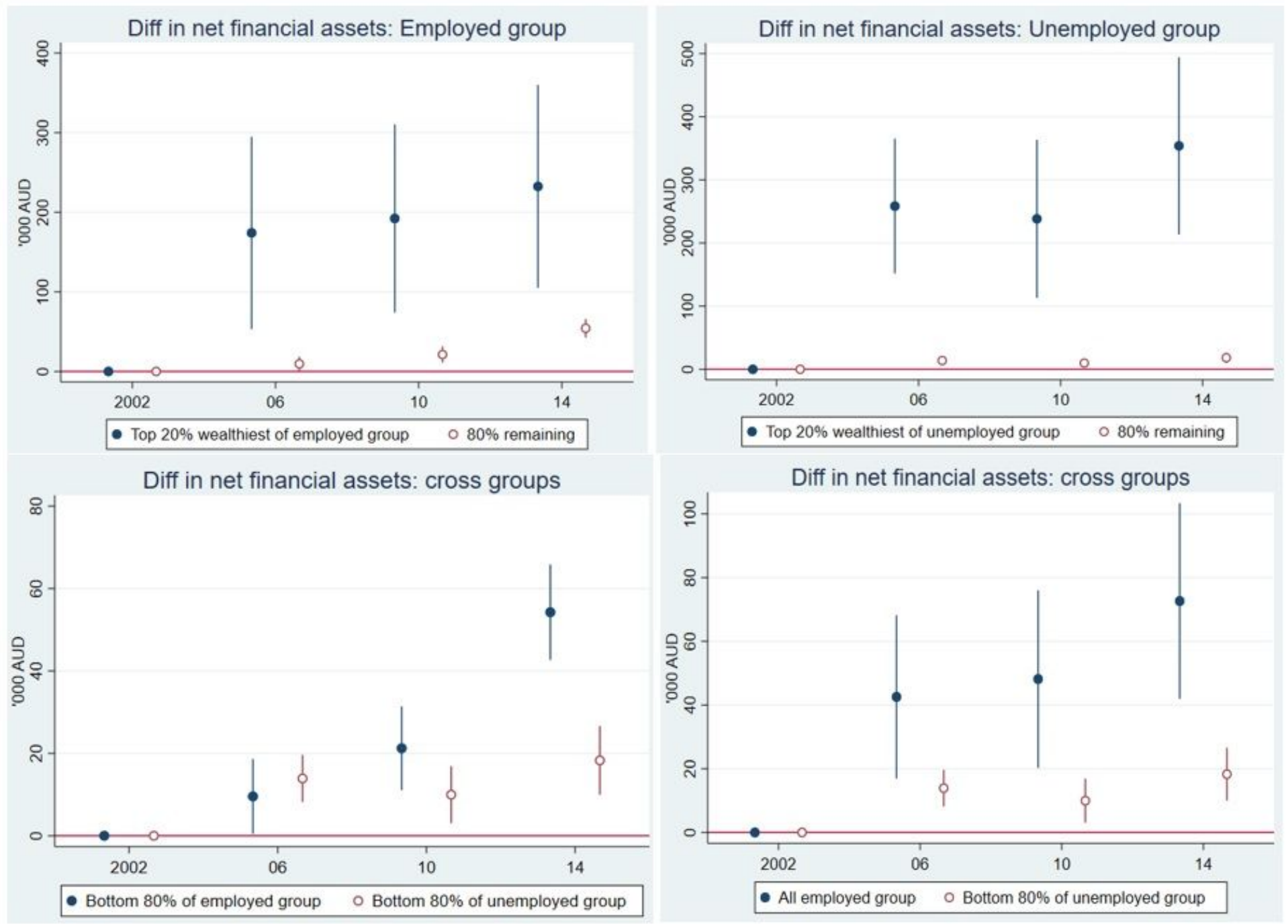

\section{Figure 8}

Relative change of net financial assets to the reference year 2002 Notes: Estimates were adjusted for age, sex, ethnicity, education, and time effect. The reference year is 2002. Net financial assets were computed from bank account balance, superannuation, cash and equity investment, trust fund, life insurance, credit card debts, and other related debts. As some of these measures were first collected in 2002, and only collected in 2002, 2006, 2010 and 2014, we thus set 2002 as the base year and the Figure only shows data in those years. The measure is in AU\$1,000 and discounted to 2002 price level. 


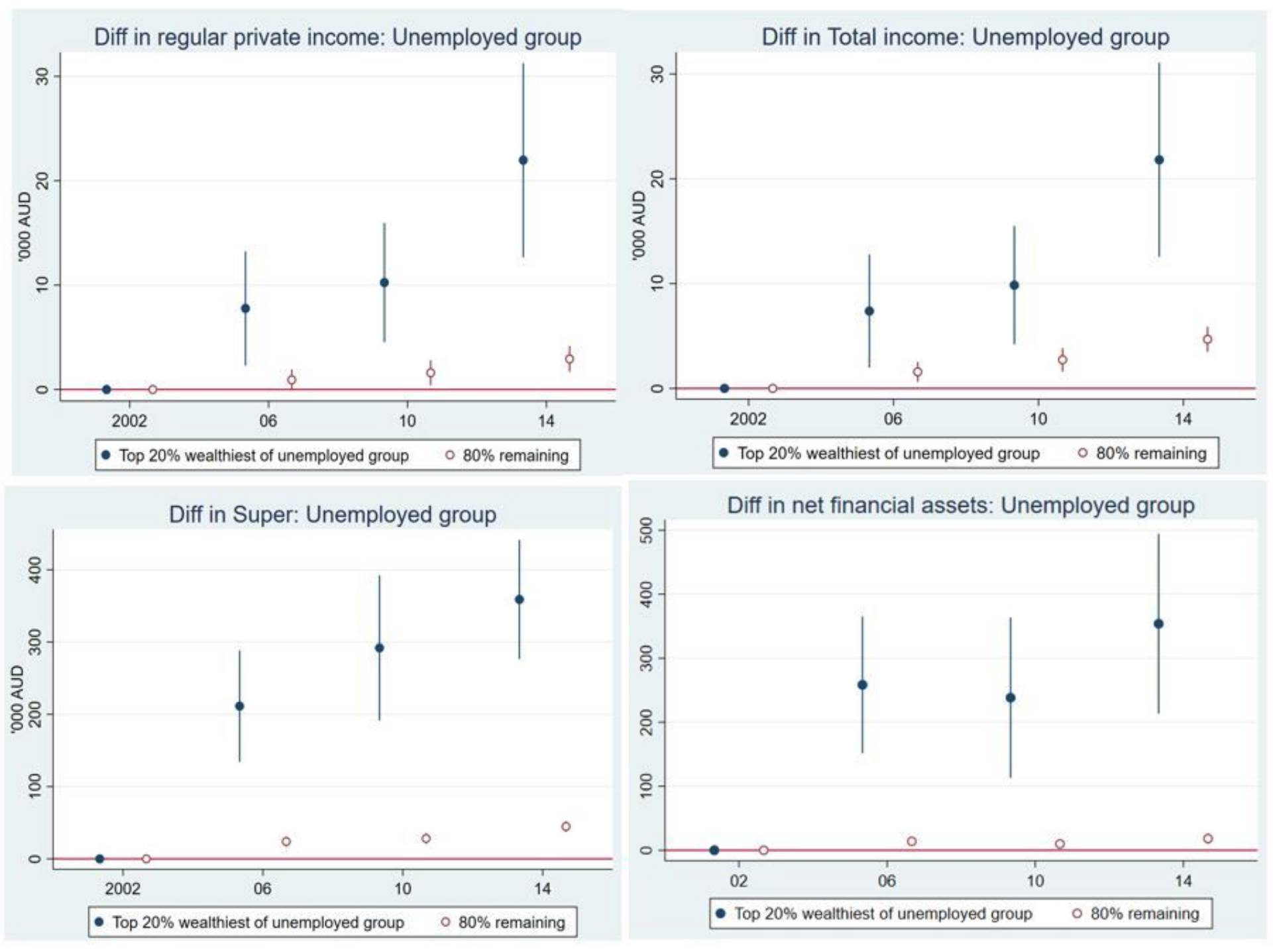

\section{Figure 9}

Rising economic inequality within the unemployed group. Notes: Estimates were adjusted for age, sex, ethnicity, education, and time effect. The reference year is the first year that the data are available. Superannuation was first collected in 2002, and measured in AU\$1,000 and discounted to 2002 price level. 

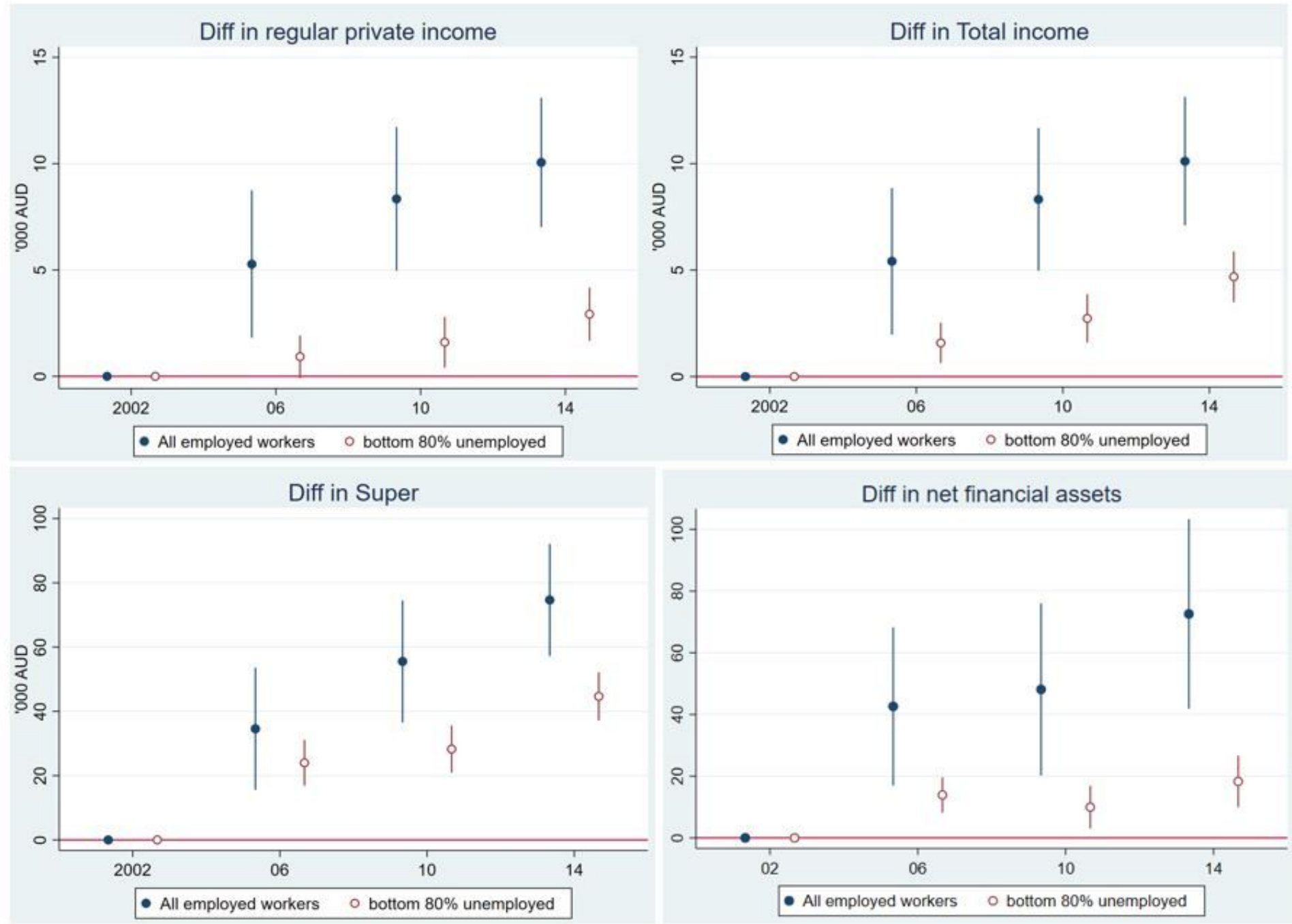

\section{Figure 10}

Rising economic inequality between the 'un-wealthy and unhealthy' and "employed group" Notes: Estimates were adjusted for age, sex, ethnicity, education, and time effect. Superannuation was first collected in 2002, and measured in AU\$1,000 and discounted to 2002 price level. 